Article

\title{
Approaches to Reduce Food Losses in German Fruit and Vegetable Production
}

\author{
Sabine Ludwig-Ohm *, Walter Dirksmeyer and Kathrin Klockgether \\ Thünen Institute of Farm Economics, Bundesallee 63, D-38116 Braunschweig, Germany; \\ walter.dirksmeyer@thuenen.de (W.D.); kathrin.klockgether@email.de (K.K.) \\ * Correspondence: sabine.ludwig-ohm@thuenen.de
}

Received: 30 September 2019; Accepted: 16 November 2019; Published: 21 November 2019

\begin{abstract}
Food losses occur in all agricultural value chains, but are especially high in the fruit and vegetable sector. This study quantifies losses of selected fruits (strawberries, apples) and vegetables (lettuce, carrots), identifies the main reasons for food losses, and assesses effective measures for the reduction of these losses. Data were collected in structured interviews with value chain actors from production to food retail and validated in regional expert workshops. Results show that in average years, about $25 \%$ of the analysed vegetables are lost at farm level. The range of fruit losses differs widely, from $15 \%$ to $20 \%$ for strawberries and only $6 \%$ to $16 \%$ for apples. Weather is a major factor for crop losses, since it can strongly affect product appearance and hence marketability in the food retail sector. There is a lack of alternative market channels for products, which do not meet the high-quality standards for fresh products in the retail sector. Effective measures to reduce food losses are protected cultivation in greenhouses or under hail nets, continuous cooling systems, improved packaging and training of staff. More cooperation and coordination between producers, wholesalers and retailers could also increase the share of marketable products.
\end{abstract}

Keywords: food losses; sustainability; fruits and vegetables; horticulture; Germany

\section{Introduction}

The Sustainable Development Goals (SDGs) established by the United Nations (UN) address in goal 12 responsible consumption and production. This includes the specific goal, 12.3, of halving the food waste at retail and consumer level and reducing food losses along the production and supply chain including post-harvest losses until 2030 [1].

In the literature, food losses are viewed from different angles against the background of research objectives and methodology. Losses in food production, in general, are accounted in order to quantify and monitor food losses in food industry value chains, e.g., for monitoring purposes in the context of achieving the SDGs [2]. In Germany, the first study on food losses and food waste estimated, in 2012, that about 11 million tonnes of food are wasted per year [3]. The study focused on the downstream stages of the value chain, thus excluding agricultural production.

Studies on food losses at downstream levels of the value chain focus mainly on losses in the food retail sector [4-8]. As well, the food processing supply chain is examined in different food industry studies $[8,9]$.

Research on food losses in primary production focuses on whole food sectors to quantify food losses, as well as on selected crops to have qualitative insights into reasons for food losses in fruit and vegetable production [10-13]. In addition, the studies of primary production vary in underlying methodology. Some researchers conduct in-field measurements while other approaches focus on expert knowledge for estimating food losses [11,13-17]. Official agricultural statistics only provide data on the harvest quantities, but harvest losses are not recorded. 
Therefore, data on field losses and on on-farm losses during harvesting and storage are not readily available. Our study addresses this information gap by analysing food losses at different levels of the value chain including primary production.

It is well-known, that fruits and vegetables are among the foods with the highest loss rates at farm level [18]. Therefore, this study focuses on the fruit and vegetable sector. Given the heterogeneous structure of this sector, the share of food losses across the various value chains for different crops is likely to vary largely. Instead of aiming at statistical representativeness or at generating valid estimates of total quantities lost for the whole fruit and vegetable sector, the study aims at:

1. estimating food losses on farm level,

2. identifying and understanding the main reasons along the value chain for these losses, and

3. developing and assessing effective measures for the reduction of these losses based on case studies of selected fruits and vegetables.

This study is part of the collaborative research project "Pathways to Reduce Food Waste (REFOWAS)", funded by the German Federal Ministry of Education and Research.

The definitions of food waste and food loss vary in the literature. Here, the terminology as defined by [19] will be used, where food waste is attributed to the consumer or household level and food losses refer to the downstream value chain stages of processing and trade, including logistics. More specifically, in this study, food losses are defined as the quantity of products suitable for consumption that have reached a minimum size and are undamaged but (1) are disposed of because of noncompliance with governmental marketing standards or quality demands of the food retail sector, (2) are not harvested or sorted out during market preparation due to fluctuations in demand and price or (3) perish after harvest. Products that show significant rotting or pest level before reaching the minimum size are not considered as food losses.

This contrasts with the definition of the European Commission (EC) for the uniform measurement of levels of food waste which is actually in preparation [20]. According to the European Commission, only harvested products are considered as food and could count as food loss [21]. However, for the purpose of our study, and following the approach of [22], it is important to include also the products lost before harvest, as these losses are relevant for the farmers and loss levels are also affected by other actors of the value chain. For example, some fruits and vegetables like lettuce and strawberries are prepared for marketing directly on the field. If there are no buyers or prices are expected to be lower than variable harvest costs, there are clear economic reasons not to harvest but to leave the marketable products on the field. According to the EC definition of food losses, these on field losses do not count as food losses, whereas they do in our investigation. The reason for this is that the produce would have been marketed if the producer prices would have been higher.

\section{Materials and Methods}

This investigation is based on case studies, which is a method to explore cause-and-effect relationships on the basis of a small number of cases [23]. The chosen comparative case study can identify similarities and differences between different cases studied. For economic reasons with regard to the analysis of case studies a number of four to ten cases is recommended [24]. Additional case studies are usually associated with successively smaller additional knowledge gains.

Case studies of different fruit and vegetable crops were carried out. Fruits and vegetables vary in storage suitability. For this reason, a product with a long shelf life and one with a short shelf life were selected for each of the two categories. In addition, the products were selected on their economic importance for German horticulture. In terms of area cultivated and value of the crop, apples are the most important fruit crop in Germany, whereas strawberries are the second [25]. For vegetable crops, carrots belong to the top three and iceberg lettuce to the top ten crops in Germany [26]. Therefore, for the fruit sector, apples and strawberries, and for the vegetable sector, carrots and lettuce were 
analysed in the case studies. For each of the crops, two major production regions in Germany were included in the analysis in order to take regional production or marketing peculiarities into account.

The case studies are based on a survey of experts. The researcher conducted face-to-face interviews with producers and decision-makers from different levels of the value chain. The interviews were structured to include the following elements:

- farm specific activities such as cultivation, storage and marketing of the selected crops,

- kind and level of food losses in their company,

- the reasons for these losses and

- their current measures to reduce these losses.

- In addition, they were invited to suggest additional countermeasures.

The selection of the respondents on farm level, producers of lettuce, carrots, strawberries and apples in the case study regions, was based on their willingness to participate. An effort was made to cover a broad range of farms with different characteristics and include the most representative farms as well as the big players in the regions. At the downstream stages of the value chain, interviews were conducted with decision-makers of specialised wholesalers for each of the crops, as well as with representatives of producer organisations who deal with a broad range of products.

In addition, for the downstream stages of the value chain, semi-structured interviews with representatives of the food retail sector and the food and beverage processing industry were conducted. A total of 81 respondents for the farm level and 29 for the downstream stages of the value chain could be evaluated (Tables 1 and 2).

Table 1. Number of respondents for the farm level.

\begin{tabular}{cccccc}
\hline Case Study & Crop & Lower Saxony & $\begin{array}{c}\text { North } \\
\text { Rhine-Westphalia }\end{array}$ & $\begin{array}{c}\text { Rhineland- } \\
\text { Palatinate }\end{array}$ & $\begin{array}{c}\text { Lake } \\
\text { Constance }\end{array}$ \\
\hline \multirow{2}{*}{ Vegetable } & Lettuce & 9 & 10 & 11 & \\
& Carrots & 10 & 10 & 10 \\
\hline \multirow{2}{*}{ Fruit } & Strawberries & 11 & & \\
& Apples & 10 & & & 10 \\
\hline
\end{tabular}

Table 2. Number of respondents for the downstream stages of the value chain.

\begin{tabular}{|c|c|c|c|c|c|}
\hline & \multicolumn{4}{|c|}{ Crop } & \multirow{2}{*}{ All Crops } \\
\hline & Lettuce & Carrot & Strawberry & Apple & \\
\hline Coordinators $^{1}$ & 4 & 4 & 2 & 7 & 4 \\
\hline Processing industry ${ }^{2}$ & & & & & 5 \\
\hline Food retail & & & & & 3 \\
\hline
\end{tabular}

${ }^{1}$ Producer organisations, wholesalers. ${ }^{2}$ Jam, juice and convenience manufacturer.

The questionnaire for interviewing the carrot producers is shown in Appendix A as an example. All questionnaires are documented in [27].

In order to clarify implausible and contradictory statements and to discover further correlations, survey results were subsequently validated in eight expert workshops with some of the interviewees of the survey and other experts from consultancy and marketing. One workshop was held for each crop and region.

Further, the expert panel qualitatively assessed the measures to reduce food losses, categorising their mitigation potential as smaller $(+)$, notable $(++)$ or high $(+++)$.

The expert survey and the expert workshops were carried out in collaboration with partners from regional horticultural consultancy services, because these practise-based partners have intensive contacts with farm managers and other value chain actors. Thus, the samples of the survey and the workshops were selected with the assistance of the consultancy service. 


\section{Results}

In this paper, we focus on the results of the analysis of primary production. The results of the investigation of food losses in the retail sector and processing industry are presented in [28].

\subsection{Brief Description of Sample and Value Chains}

In this case study, about 20 farmers were interviewed for every crop. The farm characteristics with regard to farm size, market outlets and trading activities, such as additional purchases, are described in Table 3. A number of differences between fruit and vegetable growers in the survey with regard to their market outlets and trading activities were identified:

- Most of the lettuce producers and half of the carrot producers cultivate comparatively large growing areas, as compared to the statistical averages of 16.3 ha iceberg lettuce per farm in Lower Saxony or 15.5 ha carrots per farm in Rhineland-Palatinate [29]. For fruits, there are fewer producers with larger than average growing areas involved. The statistical averages are 12.7 ha strawberries and 32 ha apples per farm in Lower Saxony [30].

- For the fruit growers, direct marketing to consumers is more important than for the vegetable growers, who are more focused on indirect marketing to producer organisations, wholesalers or food retailers.

- Nearly all apple producers supply the food processing industry. This is the market outlet for apples which do not fulfil the quality requirements of the retail sector but do meet those of the processing industry. For the other products in this survey, the processing industry is less important, as either the quality requirements differ between fresh market and industry produce (carrots) or market volumes for processing are comparatively small (lettuce).

- $\quad$ Some vegetable farms, both lettuce and carrot producers, are engaged in trading additional purchases in order to use sorting and packaging machinery to capacity.

Table 3. Characteristics of the farms interviewed.

\begin{tabular}{ccccccc}
\hline & & \multicolumn{5}{c}{ Number of Farms with } \\
\cline { 3 - 6 } Case Study & $\begin{array}{c}\text { Total } \\
\text { Number of } \\
\text { Farms }\end{array}$ & $\begin{array}{c}\text { Growing } \\
\text { Area } \\
\geq \mathbf{3 0} \text { ha }\end{array}$ & $\begin{array}{c}\text { Soles to } \\
\text { Consumers } \\
\text { Directly }\end{array}$ & $\begin{array}{c}\text { Producer } \\
\text { Organisations, } \\
\text { Wholesales, } \\
\text { Food Retailers }\end{array}$ & $\begin{array}{c}\text { Industrial Bulk } \\
\text { Consumers, } \\
\text { Convenience or } \\
\text { Food Processing } \\
\text { Industry }\end{array}$ & $\begin{array}{c}\text { Trading } \\
\text { Additional } \\
\text { Purchases }\end{array}$ \\
\hline $\begin{array}{c}\text { Lettuce } \\
\text { Washed } \\
\text { carrots }\end{array}$ & 19 & 15 & 5 & 17 & 8 & 3 \\
$\begin{array}{c}\text { Strawberries } \\
\text { Apples }\end{array}$ & 18 & 9 & 5 & 16 & 3 & 4 \\
\hline
\end{tabular}

* The cropping time of lettuce is between 5 and 10 weeks. Due to multiple cropping the growing area can be larger than the agricultural area.

To understand the causes of food losses, the various relevant activities at farm level and potential countermeasures have to be outlined because each crop has its own characteristics. Every farm of this case study takes on production and marketing activities. Depending on farm characteristics and crop specifications, storage or processing can complete these activities. Figure 1 illustrates the activities in the carrot value chain identified during the farm survey. The activities of the other three crops are documented in Appendix B. 


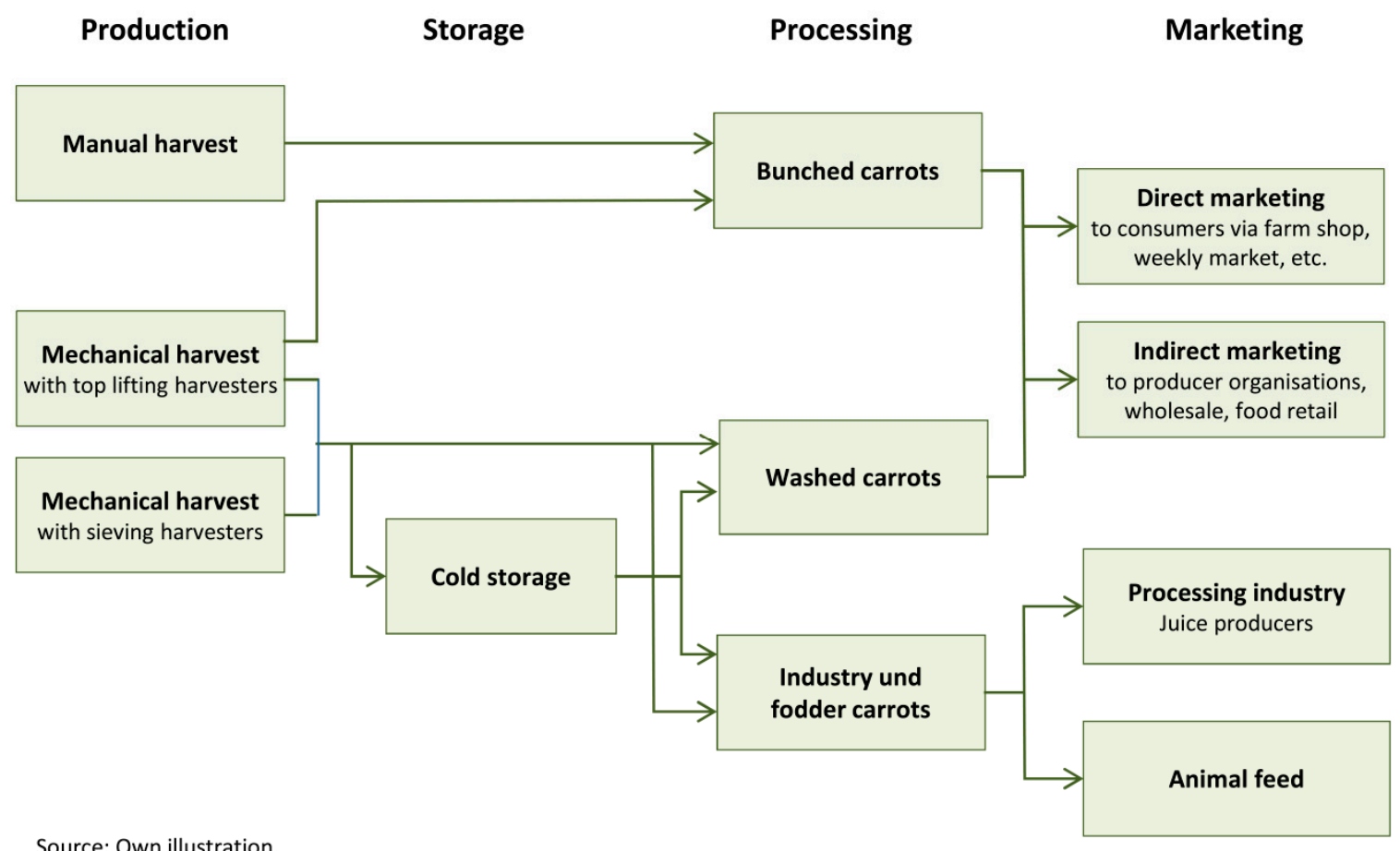

Figure 1. Activities at farm level in the carrot value chain as identified in the case study.

Carrots can be sold on the fresh market as bunched or washed carrots. Both require different harvesting techniques. Washed carrots can be stored or immediately sold to producer organisations, wholesalers and the food retail or directly to the consumer. Carrots that are not suitable for the fresh market are sorted and small amounts can be delivered to juice producers or horse-owners.

Both lettuce and strawberries are usually harvested manually and prepared for marketing directly in the field. On farm storage for these highly perishable products is very limited in time and may vary from only a few hours to a few days in cool storage. For apples, different strategies are common. Some farmers deliver to pack-houses e.g., of a farmer cooperative, where sorting, long-term storage and packaging take place, whereas other farmers have their own storage, sorting and packaging facilities.

It is common for farmers to use several market outlets, each with different quality requirements. Thus, decisions about the market channel are generally made before production begins, as for most crops, produce intended for the fresh market cannot be sold for processing purposes. For instance, the juice industry demands specific carrot varieties which are not suitable for fresh market produce. However, there are also contrary examples. Apples that cannot be marketed as fresh fruits are commonly sold to the processing industry if their quality requirements are still met. Strawberries are used on farm for processing into jams and other strawberry products. However, this is only feasible for those farmers selling their fresh strawberries directly to consumers. This reveals that the processing market channel is rather limited for the fresh market products studied, apart from apples.

\subsection{Quantification of Food Losses at Farm Level}

Food losses at the producer level can be significant (Table 4). The survey respondents stated that on average, more than $25 \%$ of lettuce and carrots are lost. For the fruits, there is a difference in farm-level food losses between easily perishable strawberries at $15 \%$ to $20 \%$ and apples at only $6 \%$ to $16 \%$, according to the farmers' estimates. Hence, food losses in fruit production tend to be lower than for vegetables. 
Table 4. Food losses at farm level ${ }^{1}$.

\begin{tabular}{ccccc}
\hline & & Good Years & Average & Bad Years \\
\hline Lettuce & & $10-15 \%$ & $\mathbf{2 5 - 3 0 \%}$ & $35-40 \%$ \\
Washed carrots & $10-15 \%$ & $\mathbf{2 5 - 4 0 \%}$ & $>50 \%$ \\
Strawberries & $\mathrm{LS}^{2}$ & $5-10 \%$ & $\mathbf{1 5 - 2 0 \%}$ & up to $40 \%$ \\
Apples & $\mathrm{NW}^{2}$ & ca. $10 \%$ & $\mathbf{6 - 1 6 \%}$ & $40-50 \%$ \\
\hline
\end{tabular}

${ }^{1}$ Included losses which are excluded by definition such as rotten or spoilt produce during cropping. ${ }^{2}$ LS $=$ Lower Saxony, NW = North Rhine-Westphalia.

However, results vary greatly due to the strong influence of varying weather conditions. To enable differentiated assessment according to the weather conditions, in the interviews the farmers referred to normal, good and bad years, representing possible but uncommonly favourable or unfavourable weather conditions. No quantitative assessment of the frequency of good and bad years could be provided. In years with unfavourable weather (bad years), losses of lettuce and strawberries can even increase up to $50 \%$. In contrast, food losses reach a maximum of $15 \%$ in years with favourable conditions (good years).

For apples, the variation in food losses is much smaller, as compared to the other crops investigated, because of two reasons: (1) Fruit thinning is an important crop management practice for apple orchards to achieve optimum fruit sizes and marketing qualities. This reduces the proportion of apples with inferior quality. (2) In contrast to other fruits, apples that cannot be sold on the fresh market are mostly delivered to the juice industry and hence do not end as food losses. Although weather conditions influence overall harvest levels for apples, the share of inferior quality produce remains more or less stable. Thus, splitting into good and bad years was not relevant for apples.

These results also include those losses which are excluded by definition as rotten or spoilt produce during cropping. This can be attributed to the data gathering procedure via interviews. During these interviews, the farm managers could not separate these losses—caused, for example, by pest infestation or fungal infections-from the losses occurring during harvest. Such problems in the recording of food losses at farm level are not untypical (see [11,17]).

\subsection{Reasons for Farm Level Food Losses}

The main reasons for food losses in the fruit and vegetable value chain, as identified by the interviewed experts in the survey, are unfavourable weather conditions, a market situation with producer prices below variable harvesting costs, farm management decisions, the strict quality standards of the food retail sector, and a lack of alternative marketing opportunities:

\section{Weather Conditions}

Unfavourable weather conditions, like frost, hail, and extreme weather events, can lead to direct food losses due to a deterioration of quality. Minor quality losses occur due to cosmetic damage, e.g., misshapen strawberries or dirty lettuce. More severe damages can even lead to total failure of the crop, for instance hail-damaged fruits. Specific weather conditions may also promote infestations by pest and diseases and lead often to products that are not suitable for human consumption, e.g., rotten fruits and vegetables.

Short-term weather conditions also have a great indirect impact on food losses. Weather affects the demand for certain fruit and vegetable products. This leads to significant variation in the marketed amounts of these products in food retail and hence also on the production level. For instance, people eat less lettuce and strawberries in rainy as compared to sunny weather. 


\section{Market Situation}

The market situation has a tremendous influence on the amount of food losses, especially for products with a short shelf life. For example, lettuce is planted and harvested in weekly staggered batches, and strawberries get continuously ripe for harvesting. The faster ripening in good weather conditions results in a high supply. Further, the demand for fruits and vegetables decreases during the holiday season or cold weather periods. Both high supply and reduced demand shift the market balance causing producer prices to fall. The respondents indicated that it is not uncommon, that producer prices fall below the harvesting costs. In these situations, the products are not harvested but left on the field.

\section{Farm Management}

Marketing agreements often include contracts of defined quantities of fruits or vegetables at a defined delivery date. In order to guarantee compliance of these sales contracts, producers tend to produce with a safety buffer, thus cultivating larger amounts on greater production areas than required in average production conditions. In years with average and better weather conditions, this leads to overproduction that may be lost on farm. These buffers amount to about $10 \%$ to $20 \%$ for lettuce and $15 \%$ to $20 \%$ for strawberries.

Additionally, too scarce personnel capacities can lead to bottlenecks in the harvesting period. Inadequate training of seasonal workers can result in less careful treatment of fruits and vegetables during harvest.

\section{Quality Standards of the Food Retail Sector}

All products examined are subject to general marketing standards of the European Union. There are also special marketing standards for lettuce, strawberries and apples, and the UNECE standard FFV-10 applies to carrots [31,32]. These standards describe minimum characteristics for the products (Table 5), define a classification in legal grades and regulate labelling.

Table 5. Minimum requirements for marketable products according to the marketing standards [31,32].

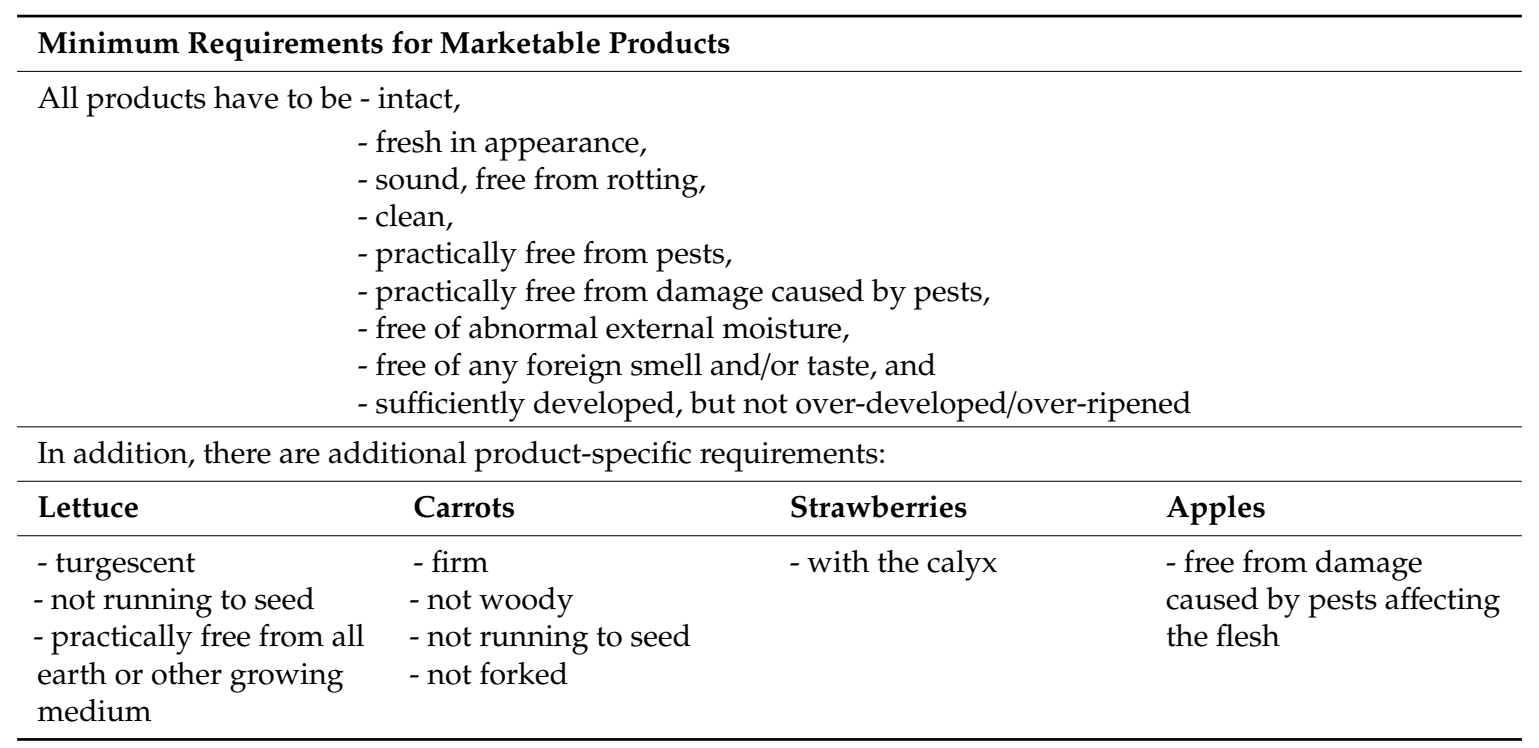

According to these marketing standards-with specific requirements for size, colour, shape and presentation-the products are classified into two classes. However, in practice, with only a few exceptions, only organic crops can be sold as Class 2 products. Thus, most of the produce has to comply with Class 1 standards. The predominant quality standards of the food retail sector with regard to these aesthetic standards are much higher and stricter than these legal ones. In addition, the food retail 
market has higher quality standards with regard to pesticide residues. As each food retail company has its own specific residue requirements, it is particularly difficult for crop production to adapt to them [33]. Both requirements-aesthetic standards and residue requirements-have a strong influence on the proportion of marketable products.

The importance of aesthetic standards as a main driver for food losses in fruit and vegetable production is also confirmed in other investigations [34-36]. Farm managers reported, during the survey, that quality standards have increased significantly over the past ten years. However, the enforcement of the quality standards is influenced by market conditions. While less perfect products are accepted when there is a shortage on the market, food retailers often complain about even the smallest quality defects when there is an oversupply on the market.

\section{Lack of Marketing Opportunities}

Products that do not meet the high-quality standards of the food retail sector influence the level of food losses, especially if marketing opportunities such as on farm or industrial processing are lacking. The results of this study show that fruit producers are more likely than vegetable producers to have diverse marketing opportunities. The options for diversification of marketing channels seem to increase from lettuce and carrots to strawberries and apples.

\subsection{Measures to Reduce Food Losses at Farm Level}

Potential measures to reduce food losses at farm level correspond to the above reasons for perishability and non-harvest. The measures are focused on preventing deterioration of quality due to poor weather conditions, extending the shelf life of fruits and vegetables, and improving marketing of all quality levels by intensifying cooperation along the value chains of fruits and vegetables.

During the workshops with experts from production, consultancy and marketing, the mitigation potential of the different measures was discussed and evaluated. In the following, the results of this evaluation are presented after the description of each measure aiming at reducing food losses at farm level.

\section{Technical Solutions to Prevent Weather Influences}

Frost protection and summer irrigation or hail protection nets help to prevent late frost and hail damage as well as sunburn in tree fruits and to ensure an adequate water supply to the plants during dry periods. Their profitability depends on the investment costs and on the probability of the weather events' occurrence. There are large differences between the regions. Frost irrigation is mainly used in the apple orchards in Lower Saxony, whereas hail protection is common especially in the fruit producing area near Lake Constance. However, in recent years hail protection became more popular in Lower Saxony's apple orchards as well.

It is expected that the frequency of extreme weather events will increase in future, and hence also the profitability of countermeasures will increase. Hail protection nets that are used on large areas have effects on the landscape. Especially in areas where tourism is important, e.g., in Lake Constance region, this may lead to conflicts and declining acceptance by neighbours or consumers.

Mitigation potential: ++ notable quantities achievable.

\section{Protected Cultivation}

Protected cultivation, for example, under glass or foil, is much less affected by poor weather conditions. Higher level of control of the production process leads to more predictable harvest times, higher yields, better product quality and less use of pesticides.

Although protected production systems increase product quality and may reduce food losses considerably, the respondents indicated that there are also disadvantages. Investment costs are high, 
and the high intensity of production is subject to criticism with respect to the environmental footprint. Consumers may be sceptical with respect to taste and sustainability.

Mitigation potential: ++ notable quantities achievable.

Cooling Systems from Field to Point of Sale

Cooling systems on farm level, such as ice water cooling for carrots or vacuum cooling for lettuce, and cooling systems in central storages, as well as humidification devices in food retail could lead to continuous cooling chains, thus preventing fruits and vegetables deteriorating at an early stage.

However, this very energy-intensive measure requires additional investment and operating costs. Therefore, cooling systems so far are used only by large farms or producer organisations. In smaller farms and in the food retail sector, improvements in cold chain management, such as the introduction of novel postharvest technologies from farm to retail logistic centres based on digital data or dry misting in retail outlets, could significantly reduce food losses [37,38].

Mitigation potential: + smaller quantities on farm level,

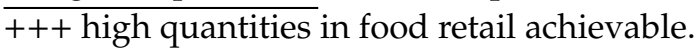

Packaging

Packaging is a common measure to reduce bruises and moisture losses. Further, the handling of packed fruits and vegetables, e.g., in food containers, flow packs or trays, is gentler and more hygienic in food retail shops. Hence, progress in the development of intelligent packaging could help to reduce food losses (see also [37]).

However, such a measure would lead to additional costs and environmental impacts due to increased use of packaging mainly consisting of plastic material.

Mitigation potential: ++ notable quantities achievable.

Training of Staff

Management improvements on farm level, e.g., better training of seasonal farm workers towards professional and gentle handling of fruits and vegetables or an improved pest control management in crop production, could help producers-especially in smaller farms-to reduce food losses.

A more specialized knowledge of how to handle fruits and vegetables professionally is important for retail staff, e.g., purchasers and shop assistants, in order to reduce losses.

Mitigation potential: ++ notable quantities achievable.

Agreements between Farmers and Food Retail

Nowadays, the relationship between fruit and vegetable producers on the one hand and retailers on the other, tend to be more characterized by lack of understanding and confrontation than by understanding and partnership. It might be expected that the value chain partners could achieve a better understanding of the constraints and difficulties of the respective partners, as a consequence, such a collaborative partnership may lead to improvements in preventing food losses. Acknowledging that fruits and vegetables are living and natural products whose quality and harvesting time cannot be completely controlled in any case, it should be possible to negotiate supply contracts for fresh market produce with a higher degree of flexibility than currently. In particular, delays in delivery or discrepancies in quantities due to unfavourable weather conditions, as well as delayed harvest/delivery due to temporarily reduced demand, should be accepted within certain boundaries in new supply contracts. This could prevent overproduction inherent to current contracts and should result in a better matching of supply and demand. The relevance of communication improvements along the value chain to reduce food losses is also highlighted by $[9,13]$.

However, such a measure seems to be difficult to implement in a strong buyer's market.

Mitigation potential: ++ notable quantities achievable. 
Greater Tolerances in Prevailing High-Quality Standards

Greater tolerances in the prevailing high-quality standards of the retail sector for size, colour and shape of fruits and vegetables, as well as for pesticide residues, could help to increase the share of marketable products without reducing nutritional physiological quality.

Ref. [39] confirm a trend towards a shifting of food losses from the food retail sector to other stages of the value chain. They further claim that the retail sector also has little interest to reduce returns in order to diminish food losses at farm level. Therefore, it seems to be difficult to implement this measure as well.

Mitigation potential: +++ high quantities achievable.

\section{Discussion and Conclusions}

For the discussion of the results of this study, it is useful to take into account that the quantification of food losses is based on a survey among growers and other experts along the value chain. No field measurements were conducted. Hence, there is uncertainty with respect to exact quantities. Ref. [12] demonstrate in their studies that growers tend to underestimate levels of food losses, whereas other experts might overestimate them by including spoilage on the field before harvest. To reduce the uncertainty of quantitative estimates, the survey results were validated in expert workshops. The advantage of the survey approach in comparison to in-field measurements is that more different crops could be included in the study.

This investigation showed that food losses at farm level can reach considerable levels and may vary greatly between farms, within the year and from year to year. The analysis of [11] found similar levels for losses in primary production of carrots and lettuce, but lower levels for strawberries (confirmed by [12]). due to the fact that strawberries in the UK are cultivated under foil or glass.

The main reasons for food losses identified in this paper are unfavourable weather conditions, oversupply, and the very strict quality standards of the food retail sector. Lower losses were found for apples and strawberries than for carrots and lettuce. For fruits, there are more processing options as compared to vegetables. However, there are differences in the quantities sold to the processing industry between apples and strawberries. The reason for this is that alternative marketing options for fresh market produce vary from crop to crop.

Measures to reduce food losses generally generate costs. Therefore, only those measures can be expected to be applied which are economically feasible. At farm level, potential measures for the reduction of food losses mainly focus on preventing quality deteriorating effects of pest and disease infestations and poor weather conditions.

Further, measures to extend the shelf life of fruits and vegetables are promising. Examples are cooling or packaging of fruits and vegetables and better training of the staff involved. Such measures should not only focus on the production level, but in particular, also on the downstream levels of the value chains of fruits and vegetables, especially on the retail level. For instance, cooling is particularly effective if a continuous cooling chain is established [37]. Training of retail stuff should focus on continuous cooling and gentle handling in particular.

Finally, it is important to intensify cooperation along the value chains of fruits and vegetables towards greater partnership of the actors because large quantities of food losses at farm level are caused by the downstream stages of the value chain $[9,13]$. The high-quality standards of the food retail sector with regard to cosmetic specifications and pesticide residues beyond legal requirements lead to high levels of non-marketable products and thus to food losses [34,36]. Fair agreements between producers and retailers with the objective to reduce food losses at all stages of the value chain should be achieved. Slightly loosening the strict quality regimes of the food retail sector and the introduction of more flexible supply contracts, thus accounting for the natural variability of the fruit and vegetable products, would help in this regard. However, due to the high degree of concentration in the food retail sector, the relationship between fruit and vegetable producers on the one hand and food retail chains on the 
other is difficult. Nevertheless, engagement of mediators without commercial interests could help take initial steps in the desired direction.

For the synthesis of results, the proposed measures to reduce food losses were evaluated by the researchers based on the experiences gained during the investigation. The criteria savings potential, feasibility, costs, motivation and acceptance were selected for the evaluation and judged with the qualitative categories low, moderate and high:

- Savings potential: degree of reduction of food losses compared to the status quo.

- Feasibility: degree of technical challenges, organisational changes and/or lack of legal certainty that may be associated with a measure.

- Costs: level of fixed and variable costs associated with the implementation of a measure.

- Motivation: willingness of management and stakeholder to implement the measure, for example, due to expected obstacles or with regard to image gains.

- Acceptance: degree of acceptance of products, production measures or technological changes by $\overline{\text { other value }}$ chain actors and consumers.

High potential savings compared to the current situation, high feasibility, highly motivated participants and high acceptance paired with low costs, ideally characterize a promising measure to reduce food losses. The evaluation of the measures in primary production using a traffic light system is visualized in Figure 2.

The measures to reduce food losses are evaluated along the different stages of the value chain, production, processing, trade and consumption. The results indicated that food losses at production level are caused by decisions taken at downstream stages of the value chain. Hence, the countermeasures to reduce those food losses concern the downstream stages, too. Therefore, the evaluation of these measures refers to the affected section of the value chain. Where there is no correlation, no element is shown in the table. 


\begin{tabular}{|c|c|c|c|c|c|c|}
\hline Measure & Sector & $\begin{array}{c}\text { Savings } \\
\text { poten- } \\
\text { tial }\end{array}$ & $\begin{array}{l}\text { Feasi- } \\
\text { bility }\end{array}$ & Costs & $\begin{array}{l}\text { Moti- } \\
\text { vation }\end{array}$ & $\begin{array}{c}\text { Accep- } \\
\text { tance }\end{array}$ \\
\hline \multicolumn{7}{|l|}{ Technical solutions to prevent weather influences } \\
\hline \multirow{4}{*}{$\begin{array}{l}\text { Irrigation as frost protection or in summer as well as hail protection nets help } \\
\text { to prevent damages on fruits and vegetables so that the share of marketable } \\
\text { fruits and vegetables can be increased. }\end{array}$} & Production & & & & & \\
\hline & Processing & & & & & \\
\hline & Trade & & & & & \\
\hline & Consumption & & & & & \\
\hline \multicolumn{7}{|l|}{ Protected cultivation } \\
\hline \multirow{4}{*}{$\begin{array}{l}\text { Protected cultivation means controllable production almost independently of } \\
\text { weather conditions. Thus, harvest quantities and sales dates can be planned } \\
\text { and consequently the share of marketable fruits and vegetables increases. } \\
\text { Surpluses can be reduced. }\end{array}$} & Production & & & & & \\
\hline & Processing & & & & & \\
\hline & Trade & & & & & \\
\hline & Consumption & & & & & \\
\hline \multicolumn{7}{|l|}{ Cooling systems from field to shop counter } \\
\hline \multirow{4}{*}{$\begin{array}{l}\text { In order to maintain freshness and quality of fruits and vegetables rapid cooling } \\
\text { of the products and maintaining the cooling chain from the harvest to the shop } \\
\text { counter are very important. }\end{array}$} & Production & & & & & \\
\hline & Processing & * & * & * & * & \\
\hline & Trade & & & & & \\
\hline & Consumption & & & & & \\
\hline \multicolumn{7}{|l|}{ Packaging } \\
\hline \multirow{4}{*}{$\begin{array}{l}\text { Packaging can help to reduce food losses by maintaining product quality on a } \\
\text { high level. Moisture losses, pressure points can be reduced, better hygienic } \\
\text { standards at the point of sale can be achieved. }\end{array}$} & Production & & & & & \\
\hline & Processing & & & & & \\
\hline & Trade & & & & & \\
\hline & Consumption & & & & & \\
\hline \multicolumn{7}{|l|}{ Training of staff } \\
\hline \multirow{4}{*}{$\begin{array}{l}\text { Management improvements on farm level, especially in smaller ones, and } \\
\text { training of food retail staff should be intensified in order to increase the } \\
\text { proportion of fresh market products and to reduce returns to producers and to } \\
\text { diminish spoilage of fruits and vegetables in food retail. }\end{array}$} & Production & & & & & \\
\hline & Processing & & & & & \\
\hline & Trade & & & & $?$ & \\
\hline & Consumption & & & & & \\
\hline \multicolumn{7}{|l|}{ Agreements between farmers and food retail } \\
\hline \multirow{4}{*}{$\begin{array}{l}\text { In order to make it easier to plan the sales volumes at farm level and to } \\
\text { produce fewer surpluses guaranteed flexible purchase agreements could be } \\
\text { established for the fresh market. }\end{array}$} & Production & & & & & \\
\hline & Processing & $*$ & * & $*$ & * & \\
\hline & Trade & & & & & \\
\hline & Consumption & & & & & \\
\hline \multicolumn{7}{|l|}{ Greater tolerances in prevailing high quality standards } \\
\hline \multirow{4}{*}{$\begin{array}{l}\text { The retail sector's high quality standards for size, colour, shape and content of } \\
\text { pesticide residues of fruit and vegetable are a major driver of food losses at } \\
\text { farm level. The same applies to the restrictive requirements for the processing } \\
\text { industry with regard to the best-before date. }\end{array}$} & Production & & & & & \\
\hline & Processing & & & & & \\
\hline & Trade & & & & & \\
\hline & Consumption & & & & & \\
\hline
\end{tabular}

* This measure is already a standard measure in the processing industry and therefore it will not be evaluated.

Source: Authors evaluation.

\begin{tabular}{|c|c|c|c|c|c|}
\hline Caption & $\begin{array}{c}\text { Savings } \\
\text { potential }\end{array}$ & Feasibility & Costs & Motivation & Acceptance \\
\hline & $\begin{array}{c}\text { low } \\
\text { moderate } \\
\text { high }\end{array}$ & $\begin{array}{c}\text { low } \\
\text { moderate } \\
\text { high }\end{array}$ & $\begin{array}{c}\text { high } \\
\text { moderate } \\
\text { low }\end{array}$ & $\begin{array}{c}\text { low } \\
\text { moderate } \\
\text { high }\end{array}$ & $\begin{array}{c}\text { low } \\
\text { moderate } \\
\text { high }\end{array}$ \\
\hline ? & \multicolumn{5}{|c|}{ An influence exists, but there is no evaluation possible. } \\
\hline
\end{tabular}

Figure 2. Evaluation of the measures suggested to reduce food losses in the value chain of fruits and vegetables.

In the last step of the project, the efficiency of the suggested measures suggested will be assessed by means of identifying (1) the associated potential of avoidable food losses, (2) their costs and (3) the implications of implementing them. Results of this evaluation, based on the methodological concepts of [40], will be available in 2020 . 
The results of this case study are only valid for the analysed fruit and vegetable crops. Therefore, further research should focus on the extension of the analysis towards other fruits and vegetables, in order to identify the variation between the different crops, and to determine general patterns across them.

Author Contributions: Conceptualization, W.D.; methodology, W.D., K.K., S.L.-O.; formal analysis, S.L.-O. and K.K.; investigation, K.K. and S.L.-O.; writing—original draft preparation, S.L.-O.; writing-review and editing, W.D.; visualization, S.L.-O.

Funding: This study is part of the collaborative research project "Pathways to Reduce Food Waste (REFOWAS)" funded by the Federal Ministry of Education and Research as part of the funding priority Social-Ecological Research [01UT1420A, 01UT1420B, 01UT1420C, 01UT1420D].

Conflicts of Interest: The authors declare no conflicts of interest.

\section{Appendix A}

\section{Questionnaire to Food Losses of Fruit and Vegetables at Farm Level}

Questionnaire Type: Carrot

Date, Hour, Interviewer name

\section{Basic Information about the Farm}

(Data processing will be anonymous, contact data used only for eventual additional questions)

Farm name, Name of farm manager, Address, Phone number, Email

Since when does the farm exist? (Year or Date)

Do you have a successor for the farm? Yes/No/Not yet defined

\section{Agricultural Area in 2015}

How much agricultural area is under cultivation in this farm? (ha)

How much is own land? (ha) Contract period for rented land? (years)

Do you exchange areas with other farmers?

What are reasons for land scarcity/competition for land in this area?

\section{Type of Production}

Conventional/Integrated production

Organic: if yes, since when? Organic producer association:

\section{Quality Management and Product Certification}

Does your farm participate in any of the following certification schemes?

(QS-GAP, GLOBAL G.A.P., IFS Standard, regional production, other)

Since year?

\section{Labour (if possible, only count labour for carrot production)}

Family labour including farm manager, permanent hired labour, seasonal hired labour (Number full-time, number part-time)

\section{Crops, Yield and Qualities in 2015}

Which crops do you produce on which acreage? (ha/\% of farm acreage)

Please consider area of double cropping e.g., for lettuce.

Please indicate also yields per ha for each crop (in $\mathrm{kg}, \mathrm{dt}$, $\mathrm{t}$ or pieces per ha)?

Please indicate units according to which figures are easier to obtain.

Crop: Vegetables open field production, thereof lettuce, thereof carrots, others,

Berries, Tree fruits, Arable crops, Fallow, Greening 


\section{Carrot Production, 2015 (and years before)}

Please specify carrot production and intended marketing channel.

Seeding from calendar week $(\mathrm{CW})$ to $\mathrm{CW}$

Harvesting from $\mathrm{CW}$ to $\mathrm{CW}$

2015 (ha, harvested quantity from field (dt/ha), share of harvested quantity that was sold (\%)),

$\varnothing$ years before (harvested quantity from field (dt/ha))

For carrots for fresh market:

- Washed carrots w/o leaves

- Carrot bunches with leaves

- Mixed bunches (carrots, leek and celery)

For carrots for industry:

- Juice production

- Freezing

Contract production: Mark if yes.

All carrot fields are irrigated? Irrigation technique?

\section{On Farm Processing and Marketing}

\section{Marketing Channels}

Which marketing channels do you use for carrots and for the other crops?

If relevant, please indicate also the specific quality.

Number of buyers?

Share of total production for carrots for fresh market/carrots for industry/others:

- Producer organisation

- Wholesale market

- Wholesaler

- Direct marketing to consumer (farmers shop, farmers market, etc.)

Packing Units for Marketing

In which packing units or packaging do you sell the carrots?

Share of production (\%) fresh/industry:

- Trailer (without washing or sorting)

- As bulk goods in big bins

- As bulk goods in $20 \mathrm{~kg}$ crates

- To bulk consumers in 5 or $10 \mathrm{~kg}$ bags

- To consumers in 1, 2 or $3 \mathrm{~kg}$ boxes or bags

- As mixed vegetable bunches

- As bunches with leaves

- As carrots for animal fodder

\section{On Farm Processing and Transport}

Which processing steps take place on farm after harvest?

Which processing steps are performed further down the value chain? Please mark.

Processing step takes place on farm/not on farm:

Mechanical harvest (top lifting harvester/share lifting harvester)

Manual harvest (bundling of carrots with leaves)

Washing

Polishing

Grading

Combining to mixed vegetable bundles 


\section{Cold storage}

Transport to buyer (distance in $\mathrm{km}$ )

Do you also buy carrots from other farms and regions, in order to use processing facilities at full capacity and to supply your buyers over a longer period? (Yes/No)

\section{Own On-Farm Storage of Carrots}

If your farm has storage and cooling facilities, please specify:

Which share of harvest is stored on farm?

Capacity $\left(\mathrm{t}\right.$ or $\left.\mathrm{m}^{3}\right)$, duration (days, weeks or months), storage losses (\%):

- Fresh air storage

- Cool storage with controlled temperature

- Controlled atmosphere storage

\section{Losses along the Value Chain and Reasons for Losses}

In order to identify losses and reasons for losses in carrot production for the fresh market, we apply the following simplified scheme (Figure A1). Losses are defined as the share of carrot production that cannot be marketed either on the fresh market, neither to the processing industry.

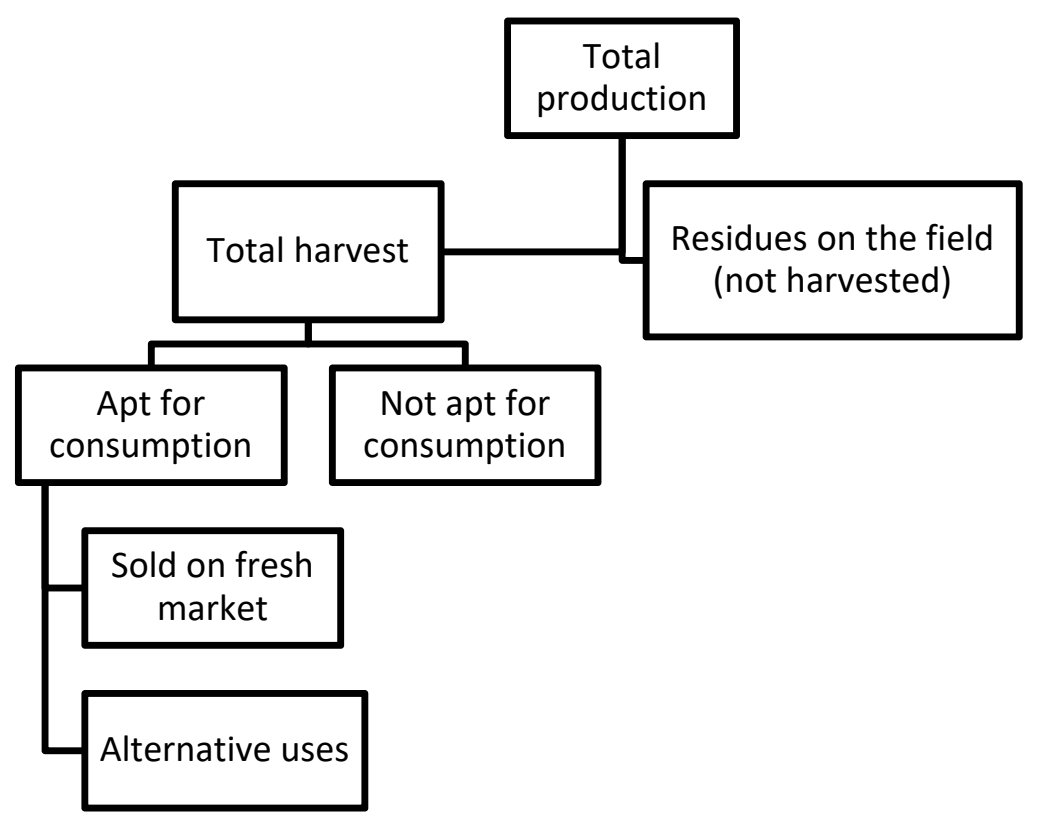

Figure A1. Simplified scheme of losses in carrot production.

\section{General Perception}

Up to consumption of fruits and vegetables by consumers, there are losses at the different steps of the value chain, e.g., (a) before harvest, due to weather conditions or plant diseases, (b) if the crop is not harvested because of insufficient market situation (c) due to quality requirements and sorting losses $(\mathrm{d})$ during processing, storage and transport.

According to your perceptions, when do most losses of carrots occur?

Losses in the value chain of carrots (\%):

On the field before harvest

During harvest

On farm: sorting, grading, washing

On farm: storage

Next step of value chain: sorting, grading 
Next step of value chain: storage, transport

In the retail, storage, etc.

At consumer level

Others

Please quantify the losses of carrots, that occur on your farm. Do you have a register of losses? (Yes/No/Partial)

Types of Losses, Quantities and Reasons of Losses on your Farm in 2015

Are different production systems or technologies associated with different loss rates?

Losses are smaller than/equal/larger than/do not know:

Conventional vs. Organic

Fresh market vs. Processing

Carrots w/o leaves vs. Bunches with leaves

With irrigation vs. Without irrigation

Cultivation on dams vs. Without dams

Do rates of losses until harvest depend on production technology? (Yes/No)

If relevant, explain production technology.

Please state reasons if a share of carrots cannot be sold in the targeted marketing channel and the intended quality. More than one reason can be stated.

Losses Pre-Harvest-Losses during Harvest-Losses Post-Harvest, 2015

Share of total production (\%) before harvest, harvest and processing, post-harvest and storage:

Abiotic Factors, Weather

- Draught, Heat

- Hail, Wind, Strong rains

- Frost

Biotic Factors

- Pests

- Diseases, Weeds

Quality Requirements

- Non-compliance with Maximum Residue Level

- Deformations

- Oversize, Too small size

Mechanical Damages during Harvest, Sorting or Grading (broken carrots)

Market Situation

Storage, Cooling

Transport

Others

\section{New Land and Quality of Carrots}

What is the importance of new land, on which no carrots or similar crops have been cultivated? for several years, or of a wide crop rotation for the successful cultivation of carrots with a good quality? Which are restrictions to implement such wide rotations?

\section{Alternative Uses of Carrots that cannot be Sold in the Fresh Market}

Please mark the relevant categories and if possible, estimate the respective quantity or share of total production. State the price difference.

Quantity (\%), Price-Markdown:

Processing Industry

- Juice factory

- Production of mixed vegetable bundles 
- Bakeries

Disposal on the field (organic fertilizer). If yes, are there phytosanitary problems? (Yes/No)

Biogas plant (Own/Others). Are there legal restrictions? (Yes/No)

Fodder for animals (Own/Other farms)

Donation, food sharing or similar

Others

Is there a cost of disposal? (€/unit)

Did you have problems in the disposal of harvest or sorting losses?

Which are the specific challenges?

Where and how do you store the wastes from sorting during winter?

\section{Losses of Revenues due to Food Losses}

Please consider the before-mentioned losses for 2015.

How much revenue were lost due to these losses?

Loss of revenue, loss of profits ( $€ /$ carrot enterprise or \%)

\section{Statements, Perceptions}

Please mark only one item of the 5 Likert scale from 5 "full agreement" to 1 "not at all agree" "Since I don't know the demand in advance, I cannot produce the exact amount that I can sell at the end of the season. Therefore, I cannot avoid overproduction."

"Since there is uncertainty of weather and growing conditions, I need to consider a risk premium on the production quantity."

"The requirements of the processing industry are too specific. Therefore I cannot sell those carrots that are not apt for fresh market to the industry."

"If quality norms for carrots were lower, there were less losses in the value chain."

"Improved communication and exchange of information with partners downstream the value chain could reduce losses."

"If more carrots would be sold as quality 2, demand of carrots of quality 1 would be reduced. In summary, this would not be profitable for my farm."

What do you think about marketing actions in the food retail on "not perfect carrots"?

(1 kg bags for $0.69 €)$ ?

\section{Measures to Reduce Losses and Associated Costs}

Are there measures (irrigation, cooling, calibration of harvesting machines, etc.) in order to reduce losses on your farm? (Yes/No)

If no, please state the most important reasons.

If yes, please estimate the costs for these measures.

Type of measure:

potential reduction of loss $(\%)$

labour need (hours/ha)

investment costs $(€)$

operational costs $(€ /$ ha)

Which measures could be implemented on the other steps of the value chain, up to the consumer? Further comments. 


\section{Appendix B}

Production

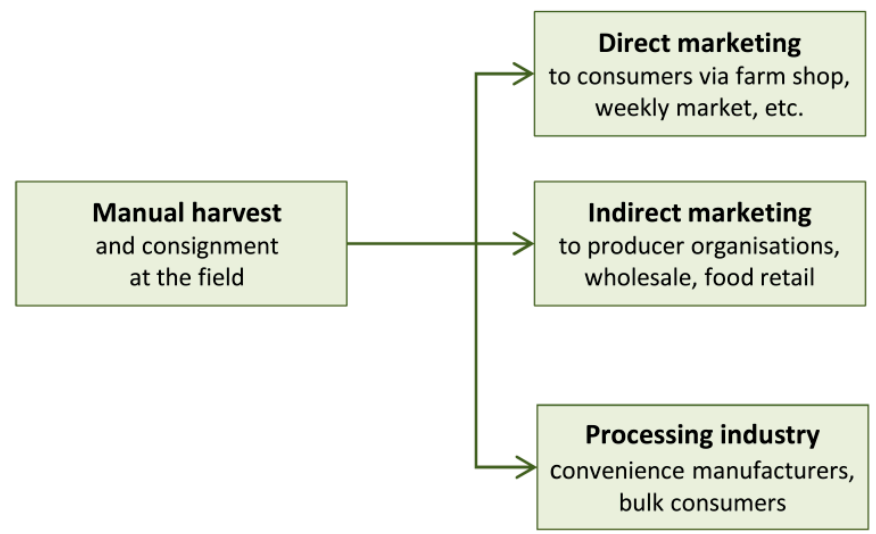

Source: Own illustration.
Marketing

\section{Direct marketing}

weekly market, etc.

bulk consumers

Figure A2. Activities at farm level in the lettuce value chain as identified in the case study.

Production

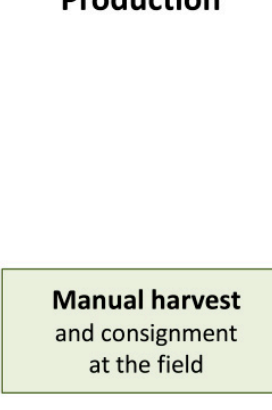

Source: Own illustration.

Figure A3. Activities at farm level in the strawberry value chain as identified in the case study.

\section{Marketing}

Processing

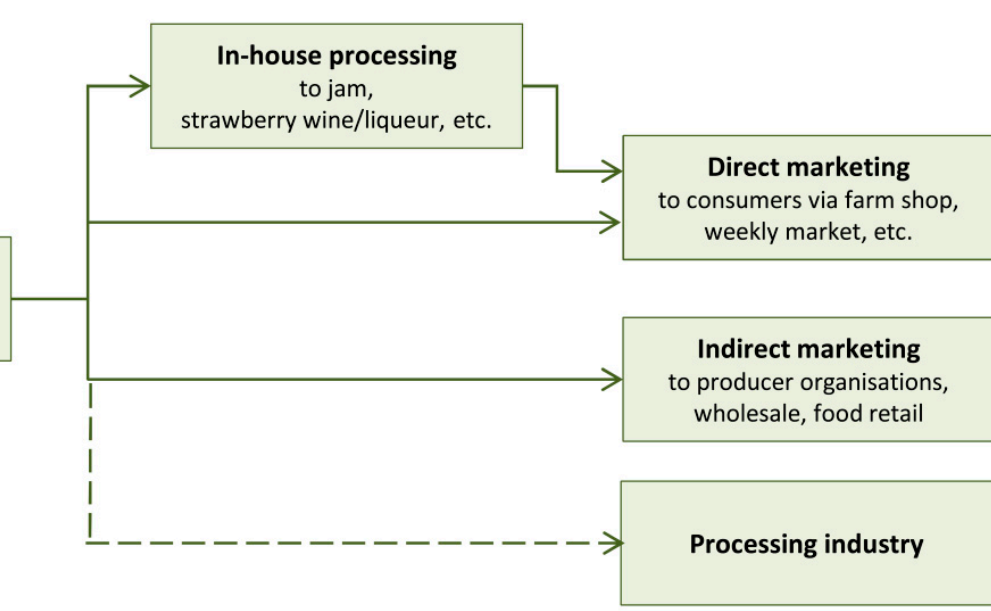




\section{Production}

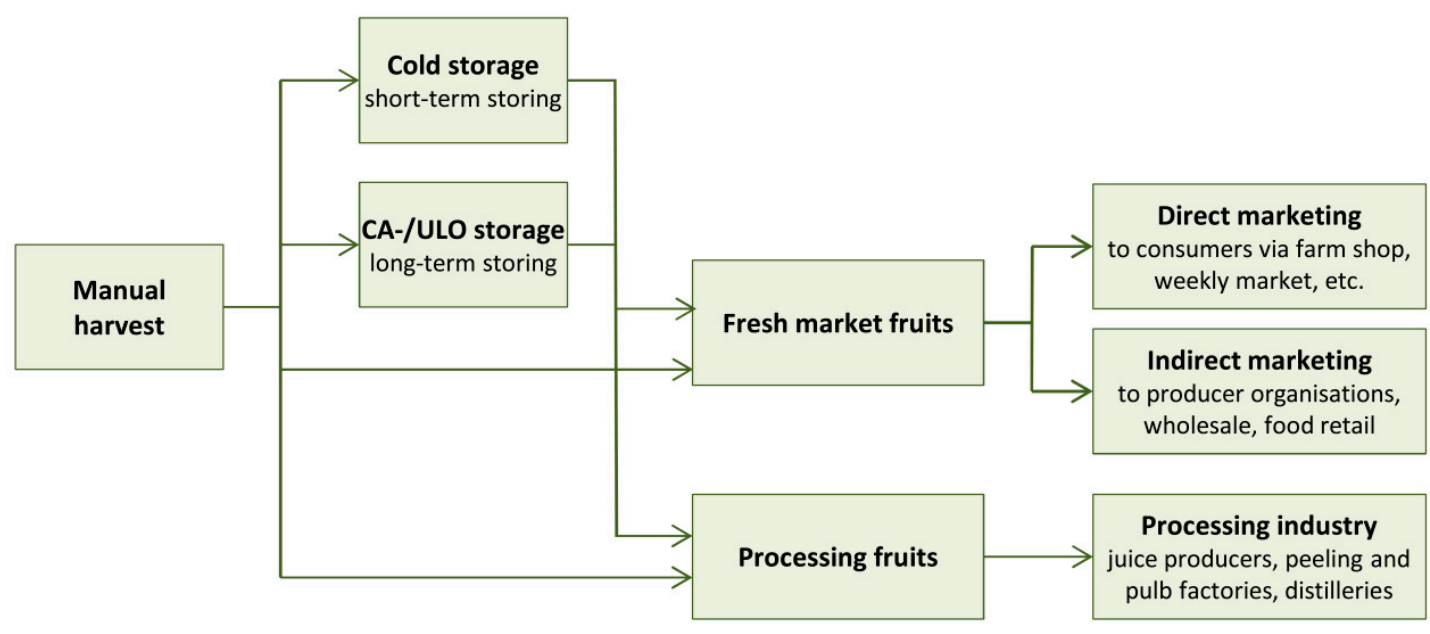

Source: Own illustration.

Figure A4. Activities at farm level in the apple value chain as identified in the case study.

\section{References}

1. UN (United Nations). Resolution Adopted by the General Assembly on 25 September 2015. Transforming Our World: The 2030 Agenda for Sustainable Development. UN Doc. A/RES/70/1. Available online: https:/www.un.org/en/development/desa/population/migration/generalassembly/docs/ globalcompact/A_RES_70_1_E.pdf (accessed on 26 September 2019).

2. Schmidt, T.; Schneider, F.; Leverenz, D.; Hafner, G. Lebensmittelabfälle in Deutschland_Baseline 2015; Johann Heinrich von Thünen-Institut, Ed.; Thünen Report 71; Johann Heinrich von Thünen-Institut: Braunschweig, Germany, 2019. [CrossRef]

3. Kranert, M.; Hafner, G.; Barabosz, J.; Schuller, H.; Leverenz, D.; Kölbig, A.; Schneider, F.; Lebersorger, S.; Scherhaufer, S. Ermittlung der weggeworfenen Lebensmittelmengen und Vorschläge zur Verminderung der Wegwerfrate bei Lebensmitteln in Deutschland; Federal Ministry of Food, Agriculture and Consumer: Protection, Germany, 2012.

4. Buzby, J.C.; Wells, H.F.; Hyman, J. The Estimated Amount, Value, and Calories of Postharvest Food Losses at the Retail and Consumer Levels in the United States; United States Department of Agriculture, Ed.; Economic Information Bulletin; United States Department of Agriculture: Washington, DC, USA, 2014; Volume 121.

5. Lebersorger, S.; Schneider, F. Food loss rates at the food retail, influencing factors and reasons as a basis for waste prevention measures. Waste Manag. 2014, 34, 1911-1919. [CrossRef] [PubMed]

6. Filimonau, V.; Gherbin, A. An exploratory study on food waste management practices in the UK grocery retail sector. J. Clean. Prod. 2017, 167, 1184-1194. [CrossRef]

7. Mattsson, L.; Williams, H.; Berghel, J. Waste of fresh fruit and vegetables at retailers in Sweden-Measuring and calculation of mass, economic cost and climate impact. Resour. Conserv. Recycl. 2018, 130, 118-126. [CrossRef]

8. WRAP. Quantification of Food Surplus, Waste and Related Materials in the Grocery; WRAP: Banbury, UK, 2016; Available online: https:/www.farminguk.com/content/knowledge/Quantification-of-food-surplus-wasteand-related-materials-in-the-grocery-supply-chain(4040-684-286-3476).pdf (accessed on 22 October 2019).

9. Richter, B.; Bokelmann, W. Approaches of the German food industry for addressing the issue of food losses. Waste Manag. 2016, 48, 423-429. [CrossRef] [PubMed]

10. WRAP. Food Waste in Primary Production in the UK; WRAP: Banbury, UK, 2019; Available online: http: //www.wrap.org.uk/sites/files/wrap/Food_waste_in_primary_production_in_the_UK_0.pdf (accessed on 22 October 2019).

11. Beausang, C.; Hall, C.; Toma, L. Food waste and losses in primary production: Qualitative insights from horticulture. Resour. Conserv. Recycl. 2017, 126, 177-185. [CrossRef] 
12. WRAP. Food Waste in Primary Production - A Preliminary Study on Strawberries and Lettuce; WRAP: Banbury, UK, 2017; Available online: http://www.wrap.org.uk/sites/files/wrap/Food_waste_in_primary_production_ report.pdf (accessed on 22 October 2019).

13. Meyer, C.H.; Hamer, M.; Frieling, D.; Oertzen, G. Lebensmittelverluste von Obst, Gemüse, Kartoffeln Zwischen Feld und Ladentheke-Ergebnisse Einer Studie in Nordrhein-Westfalen; Landesamt für Natur, Umwelt und Verbraucherschutz Nordrhein-Westfalen (LANUV): Recklinghausen, Germany, 2018; Fachbericht 85.

14. Johnson, L.K.; Dunning, R.D.; Gunter, C.C.; Bloom, J.D.; Boyette, M.D.; Creamer, N.G. Estimating on-farm food loss at the field level: A methodology and applied case study on a North Carolina farm. Resour. Conserv. Recycl. 2018, 137, 243-250. [CrossRef]

15. Schmied, E.; Mayerhofer, J.; Schwödt, S.; Obersteiner, G. Gleaning activities as contribution to food waste reduction. In Proceedings of the Sardinia 2017, 16th International Waste Management and Landfill Symposium, Cagliari, Italy, 2-6 October 2017.

16. Schneider, F.; Part, F.; Göbel, C.; Langen, N.; Gerhards, C.; Kraus, G.F.; Ritter, G. A methodological approach for the on-site quantification of food losses in primary production: Austrian and German case studies using example of potato harvest. Waste Manag. 2019, 86, 106-113. [CrossRef] [PubMed]

17. Leibetseder, M. Lebensmittelabfälle in der landwirtschaftlichen Produktion-Abschätzung des Verlusts von Obst und Gemüse in der Landwirtschaft und während des Transportes zum Händler. Master's Thesis, Institute of Waste Management, University of Natural Resources and Life Sciences, Vienna, Austria, 2012.

18. Gustavsson, J.; Cederberg, C.; Sonesson, U.; van Otterdijk, R.; Meybeck, A. Global Food Losses and Food Waste-Extent, Causes and Prevention; Food and Agriculture Organization of the United Nations (FAO): Rom, Italy, 2011.

19. Hafner, G.; Barabosz, J.; Leverenz, D.; Maurer, C.; Kranert, M.; Göbel, C.; Friedrich, S.; Ritter, G.; Teitscheid, P.; Wetter, C. Analyse, Bewertung und Optimierung von Systemen zur Lebensmittelbewirtschaftung, Teil I: Definition der Begriffe "Lebensmittelverluste" und "Lebensmittelabfälle". Müll Abfall_Fachzeitschrift Abfall Ressourcenwirtschaft 2013, 11, 601-609.

20. European Commission Delegated Decision (EU) of 3 May 2019 Supplementing Directive 2008/98/EC of the European Parliament and of the Council as Regards a Common Methodology and Minimum Quality Requirements for the Uniform Measurement of Levels of Food Waste. Available online: https: //ec.europa.eu/transparency/regdoc/rep/3/2019/EN/C-2019-3211-F1-EN-MAIN-PART-1.PDF (accessed on 26 September 2019).

21. European Parliament Regulation (EC) No 178/2002 of the European Parliament and of the Council of 28 January 2002 Laying Down the General Principles and Requirements of Food Law, Establishing the European Food Safety Authority and Laying Down Procedures in Matters of Food Safety. Available online: https://mobil.bfr.bund.de/cm/343/2002_178_en_efsa.pdf (accessed on 26 September 2019).

22. Johnson, L.K.; Bloom, J.D.; Dunning, R.D.; Gunter, C.C.; Boyette, M.D.; Creamer, N.G. Farmer harvest decisions and vegetable loss in primary production. Agric. Syst. 2019, 176, 102672. [CrossRef]

23. Göthlich, S.E. Fallstudien als Forschungsmethode: Plädoyer für einen Methodenpluralismus in der Deutschen Betriebswirtschaftlichen Forschung; No 578; Manuskripte aus den Instituten für Betriebswirtschaftslehre der Universität Kiel: Kiel, Germany, 2003.

24. Borchardt, A.; Göthlich, S.E. Erkenntnisgewinnung durch Fallstudien. In Methoden der Empirischen Forschung, 3rd ed.; Albers, S., Klapper, D., Konradt, U., Walter, A., Wolf, J., Eds.; Gabler: Wiesbaden, Germany, 2009; pp. 33-48.

25. AMI-Agrarmarkt Informations-Gesellschaft mbH. AMI Markt Bilanz Obst 2019; AMI-Agrarmarkt Informations-Gesellschaft mbH: Bonn, Germany, 2019.

26. AMI-Agrarmarkt Informations-Gesellschaft mbH. AMI Markt Bilanz Gemüse 2019; AMI-Agrarmarkt Informations-Gesellschaft mbH: Bonn, Germany, 2019.

27. Schmidt, T.; Baumgardt, S.; Blumenthal, A.; Burdick, B.; Claupein, E.; Dirksmeyer, W.; Hafner, G.; Klockgether, K.; Koch, F.; Leverenz, D.; et al. Wege zur Reduzierung von Lebensmittelabfällen—Pathways to Reduce Food Waste (REFOWAS): Maßnahmen, Bewertungsrahmen und Analysewerkzeuge Sowie Zukunftsfähige Ansätze für Einen Nachhaltigen Umgang mit Lebensmitteln unter Einbindung Sozio-Ökologischer Innovationen; Johann Heinrich von Thünen-Institut, Ed.; Thünen Report 73; Johann Heinrich von Thünen-Institut: Braunschweig, Germany, 2019; Volume 2, Available online: https://www.thuenen.de/media/publikationen/ thuenen-report/Thuenen-Report_73_Vol2.pdf (accessed on 22 October 2019). [CrossRef] 
28. Ludwig-Ohm, S.; Dirksmeyer, W. REFOWAS-Fallstudie Obst und Gemüse: Lebensmittelverluste in Verarbeitungsindustrie und Lebensmitteleinzelhandel (LEH); DGG-Proceedings; Deutsche Gartenbauwissenschaftliche Gesellschaft (DGG): Berlin, Germany, 2019; (Under Review).

29. Strohm, K.; Garming, H.; Dirksmeyer, W. Entwicklung des Gemüsebaus in Deutschland von 2000 bis 2015 : Anbauregionen, Betriebsstrukturen, Gemüsearten und Handel; Johann Heinrich von Thünen-Institut, Ed.; Thünen Working Paper 56; Johann Heinrich von Thünen-Institut: Braunschweig, Germany, 2016; Available online: https://www.thuenen.de/media/publikationen/thuenen-workingpaper/ThuenenWorkingPaper_56. pdf (accessed on 22 October 2019).

30. Garming, H.; Dirksmeyer, W.; Bork, L. Entwicklungen des Obstbaus in Deutschland von 2005 bis 2017: Obstarten, Anbauregionen, Betriebsstrukturen und Handel; Johann Heinrich von Thünen-Institut, Ed.; Thünen Working Paper 100; Johann Heinrich von Thünen-Institut: Braunschweig, Germany, 2018; Available online: https: //www.thuenen.de/media/publikationen/thuenen-workingpaper/ThuenenWorkingPaper_100.pdf (accessed on 22 October 2019).

31. European Commission Implementing Regulation (EU) No 543/2011 of 7 June 2011. Available online: www.eur-lex.europa.eu/legal-content/EN/TXT/PDF/?uri=CELEX:32011R0543 (accessed on 26 September 2019).

32. UNECE (United Nations Economic Commission for Europe) Standard FFV-10 Concerning the Marketing and Commercial Quality Control of Carrots. 2017 Edition. Available online: https:/www.unece.org/fileadmin/ DAM/trade/agr/standard/standard/fresh/FFV-Std/English/10_Carrots.pdf (accessed on 26 September 2019).

33. Holthusen, H.H.F. Pflanzenschutz im Deutschen Obstbau: Herausforderungen aus Sicht des Alten Landes. Presented at the 15th Swiss Growing Day, St. Gallen, Switzerland, 24 February 2017; Available online: https:/www.agroscope.admin.ch/agroscope/de/home/aktuell/veranstaltungen/schweizerobstkulturtag.html (accessed on 24 May 2018).

34. Frieling, D.; Stricks, V.; Wildenberg, M.; Schneider, F. The beauty and the beast-How quality management criteria at supermarkets create food waste. In Proceedings of the Perspectives on Managing Life Cycles-6th International Conference on Life Cycle Management, Gothenburg, Sweden, 25-28 August 2013.

35. Runge, F.; Lang, H. Lebensmittelverluste in der Landwirtschaft durch Ästhetik-Ansprüche an Obst und Gemüse-Gründe, Ausmaß und Verbleib. Berichte Landwirtschaft 2016, 94. [CrossRef]

36. De Hooge, I.E.; van Dulm, E.; van Trijp, H.C.M. Cosmetic specifications in the food waste issue: Supply chain considerations and practices concerning suboptimal food products. J. Clean. Prod. 2018, 183, 698-709. [CrossRef]

37. Porat, R.; Lichter, A.; Terry, L.A.; Harker, R.; Buzby, J. Postharvest losses of fruit and vegetables during retail and in consumers' homes: Quantifications, causes, and means of prevention. Postharvest Biol. Technol. 2018, 139, 135-149. [CrossRef]

38. CORDIS-EU Research Results. Waste Reduction and Quality Improvements of Fruits and Vegetables via an Innovative and Energy-Efficient Humidification/Disinfection Technology. Available online: https: //cordis.europa.eu/project/rcn/193303/factsheet/en (accessed on 22 October 2019).

39. Eriksson, M.; Ghosh, R.; Mattsson, L.; Ismatov, A. Take-back agreements in the perspective of food waste generation at the supplier-retailer interface. Resour. Conserv. Recycl. 2017, 122, 83-93. [CrossRef]

40. Goosens, Y.; Wegner, A.; Schmidt, T. Sustainability Assessment of Food Waste Prevention Measures: Review of Existing Evaluation Practices. Front. Sustain. Food Syst. 2019, 3, 90. [CrossRef]

(C) 2019 by the authors. Licensee MDPI, Basel, Switzerland. This article is an open access article distributed under the terms and conditions of the Creative Commons Attribution (CC BY) license (http://creativecommons.org/licenses/by/4.0/). 